\title{
A computing program derived from Chree's method
}

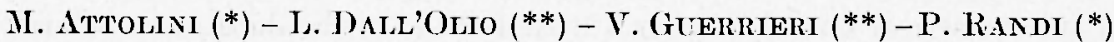

\author{
Ricevuto il 23 Novembre 1968
}

\begin{abstract}
SUMMary. - A computing program has been actived for having information from stationary time series.

The technique utilized is that of superposed epochs (Chree's method), adapted by using large computers.

This technique gives evidence for a phenomenon and statistical consistency is provided.

The program described elaborates unlimited numbers of data and epochs the maximum length of which is 2000 numerical data.
\end{abstract}

Riassunto. --. E stato fatto un programma di calcolo per ottenere informazioni da serie temporali stazionarie.

La tecnica usata è quella di sovrapposizione di epoche (metodo di (hree), di cui se ne propone una modifica per essere utilizzata con grandi calcolatori. tistica.

Si mette in evidenza un fenomeno e se ne discute la consistenza sta-

Il programma descritto elabora un mumero illinitato di dati e di epoche la cui lunghezza massina è fissata in 2000 dati numerici.

\section{INTRODUCTION.}

In graphic registrations, or tabulations of some quantities, that constitute a stationary time series, the problem that arises is that of testing the consistency of certain particular phenomenon that are noticed in correspondence with determinate physical events $\left(^{1}\right)\left({ }^{2}\right)$.

(*) Istituto di Fisica Lniversità di Bologna. Gruppo Italiano di Fisica Cosmica. Consiglio Nazionale delle Ricerche. Nucleare.

(**) Centro di Calcolo di Bologna. Comitato Nazionale per l'Energia 
The graphed or tabulated quantities correspond in some way to these physical events that, by other methods, can be localized in time.

I tipical example is constituted by the oscillations observed in recorded cosmic radiation in correspondence with the sudden commencement of magnetic storms, whose position in time can be found by observing the magnetograms.

The phenomenon we must test can be approximated to the order of the statistical fluctuation (or a little better) of the data series whose registration is examined, and therefore necessitates a particular analysis for determining the characteristics.

In this work we propose a solution to the problem by using the technique of Chree of superposed epochs $\left({ }^{3}\right)$ for using electronic computers and completing it by an ulterior analysis for proving the statistical consistency of the results regarding the width and the duration of the phenomena. Besides, the maximum temporal position is localized which allows us to visualize the bond between the registrated phenomena and the physical events which are bound to it.

\section{MeThoD.}

A stationary time series can be thought of as a linear combination of type:

$$
I(t)=A(t)+\varepsilon,
$$

being $A(t)$ the systematic part and $\varepsilon$ the random one of the series. The aim of pointing out the phenomena according to the type of series which we want to separate, we must utilize a preventive filter operation (') of which a computing program $\left({ }^{5}\right)$ already exists.

In the numerical filtering steps the reduction of the influences by the random part in the residual series allows to note the phenomenon without modifying the structure.

Let us call $q_{r}(r=1,2, \ldots \ldots, n)$ the corresponding values in the recording of the physical events which we consider responsible for the phenomenon that we must examine.

Let us construct the matrix:

$$
\begin{aligned}
& p_{1,1} \quad p_{1,2} \quad p_{1,3} \ldots \ldots p_{2, l} q_{1} d_{1,1} d_{1,2} \ldots \ldots d_{1, m} \\
& \begin{array}{llllllllll}
p_{2,1} & p_{2.2} & p_{3,3} \ldots \ldots p_{2,1} & q_{2} & d_{2,1} & d_{2,2} \ldots \ldots d_{2, m}
\end{array}
\end{aligned}
$$

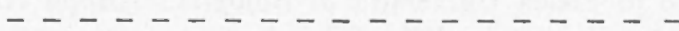

$$
\begin{aligned}
& \text { - - - - }-\cdots-\cdots-\cdots \\
& p_{n, 1} p_{n, 2} p_{n, 3} \ldots \ldots p_{n, t} q_{n} d_{n, 1} d_{n, 2} \ldots \ldots d_{n, m}
\end{aligned}
$$


being $p_{s, r}(s=1,2, \ldots \ldots l)$ the numerical values of the $l$ positions preceeding the position of the event $q$ and $d_{t, r}$ the values of the $m$ positions following.

Each row of the matrix, $n \times R(R=l+m+1)$, contains the elements of each one of the $n$ epochs $\left({ }^{3}\right)$.

As for random part, between the variance of $y_{i}(i=1,2, \ldots, r)$ (obtained by adding and by averaging per columns the elements of the matrix:

$$
\begin{array}{ll}
y_{i}=\frac{1}{n} \sum_{r=1}^{n} p_{r, i} & (i=1,2, \ldots \ldots l) \\
y_{l+1}=\frac{1}{n} \sum_{r=1}^{n} q_{r} & \\
y_{i+l+1}=\frac{1}{n} \sum_{r=1}^{n} d_{r, i} & (i=1,2, \ldots \ldots m)
\end{array}
$$

of which $\bar{s}:$ is the estimate) and the mean variance of each of the $n$ epochs (of which $S$ - constitues the estimate) is the relation

$$
\bar{S}^{2}=n S_{e}^{2}
$$

The standard deviation $S_{c}^{2}$ is

$$
\text { s.d. }\left(S^{2}\right)=S_{e}^{2} \sqrt{\frac{2}{R-1}}=\frac{S^{2}}{n} \sqrt{\frac{2}{R-1}} .
$$

Finally :

$$
S=\sqrt{\frac{R-1}{2}}\left(n \frac{S_{e}^{2}}{\bar{S}^{2}}-1\right)
$$

Being $n$ the number of the superposed epochs, represents, in stiandard deviation units the true shift of the data series from random behaviour, and $S$ is the significance level of the phenomenon in the series.

The lenght $R$ of the epoch depends from the physical problem examined. The preceding $\left(p_{s, r}\right)$ and successive $\left(d_{t, r}\right)$ data of the event may be equally populated $(l=m)$.

Since the effects of a certain physical event are generally allayed in the recordings, whether for the inertia of the system on which it acts or by the recorder that smooths the various phenomena exploring them in a large width, a time contraction of the elements forming the epoch is elaborated. Such an operation permits a better 
localisation of the phenomenon studied and ulteriorly decreases that statistical fluctuation of the series.

The problem studied will guide the choice of such a contraction. The relation (1) is modified:

$$
s(k)=\sqrt{\frac{\frac{R}{k}-1}{2}\left(n k \frac{S_{e k}^{2}}{s^{2}}-1\right) \quad\left(\frac{R}{k} \text { integer }\right)}
$$

being $k$ the order of the temporal contraction $S_{e k}^{-}$the variance of the contracted mean epoch.

$A$ rigth representation of $S(k)$ will permits useful considerations on the localisation and duration of the phenomena studied.

\section{Description of thF PRogram.}

The program has been carried out at "Centro di Calcolo del "NEN" in Bologna using the FORTRAN IV language versione 13 under the IBSYS $7094 / 7040$ DCS monitor control.

The data number that can be elaborated is pratically unlimited; the maximum allowed number of elements of the epoch is 2000 . This number is extremely sufficient for many problems but it can also be increased by modifying the appropriate statements.

The number $n$ of superposed epochs is 200. This number may be increased by modifying the appropriate statement, but attention must be made in order of the approximation due to the machine representation of the value of the elements, that arises when mean eporh is computed.

The program allows also to group, $k$ by $k$, the set of elements in the mean epoch for giving an epoch whose variance is $k$ times less than that of the original mean epoch.

This procedure allows a better accuracy in the computing of the average width of the studied event without phase changes, because, if $k$ is odd, $y_{l+1}$ will always be in the middle of the interval of the obtained epoch.

The program can also be informed to ignere the not good elements of the series without modifying the input data series cards.

It is useful to note $\bar{S}^{2}$ is computed not using the mean of the variances of each row, but the mean of the variances concerning the consecutive epochs, each $R$ elements long, obtained considering all 
the time data series (except the not good elements); the variance computed in this way tends to the true variance of the series.

\section{Output.}

Normally we can obtain a following list:

a) input tape (NTPI)

b) number of data per input card (NIOS)

c) input FORMAT (FR1)

d) print FORMLT (FR2)

e) punch FORMAT (FR3)

f) number of superposed epochs or $q$ (NKPO)

g) number of $p$ (NOPR)

h) number of $d$ (NODO)

i) index of $q$ positions in time-series (KPO)

j) number of utilized data

k) number of consecutive epochs

l) mean epoch information:

1) mean variance (ISGR2)

2) standard deviation (SE)

3) variance (SIGMA)

4) significance level (S)

5) DIFVER $=$ SIGMA $-\frac{\text { SIGR2 }}{\text { NKPO }}$

$m$ ) length of mean epoch (R)

$n$ ) elements of mean epoch (ELM)

o) grouped epoch information:

1) number of elements (R)

2) GROUPS

3) SIGMA

4) $\mathrm{S}$

5) DIFVER

p) local maxima of $S$ are computed and the following information are listed:

1) $\mathrm{S}$

2) SIGLIA

3) type of groupping (GROUPS)

4) $\mathrm{R}$ 
If the restart procedure is required, the normal list is like the proceeding from $l$ ) to $p$ ).

If the program recognizes errors during his flow appropriate diagnostics are printed.

Order of datsa carjos DeCh SET-LP.

All cards must be included in the order shown below,

a) Start procedure (Fig. 1)

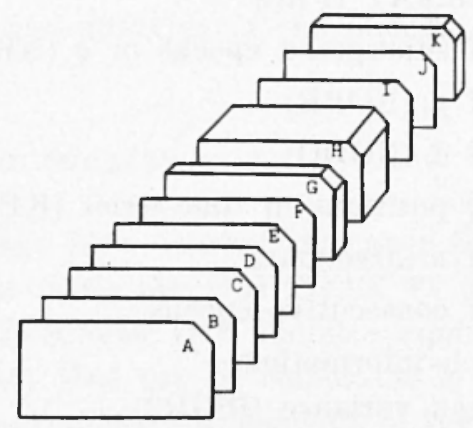

Figr. 1

* $\Lambda$ * Parameter card for starting and groupping

*13* Variable format card for time series input data

*C* Variable format card for printout mean epoch

*I)* Variable format card for punched input epoch

*I* Time series data parameter card

* F* Epoch parameter card

*G* qi index card

*I* Time series data

*I* ENI punched in col. $1-3$

*J* Number of groups to be discarded

*K* Index of group to be discarded

b) Restart procedure (Fig. 2)

$*_{A} *$ Parameter card for restarting and groupping

* B* Blank card 
${ }^{*} \mathrm{C}^{*}$ Jike in a)

*I) * Like in a)

${ }^{*} \mathrm{~L}^{*}$ Mean epoch parameter card

*M* Mean epoch elements.

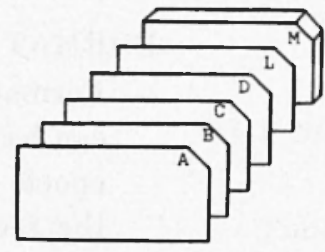

Fig. 2

Card preparation.

\begin{tabular}{|c|c|c|}
\hline $\begin{array}{c}\text { Card } \\
\text { columns }\end{array}$ & $\begin{array}{l}\text { Corresponding } \\
\text { variable }\end{array}$ & Description \\
\hline$* A *$ card & & FORMAT (4I3) \\
\hline $1-2$ & K'TEST & $\begin{array}{l}-=1 \text { if restart procedure is } \\
\text { required } \\
\neq 1 \text { if start procedure' is re- } \\
\text { quired }\end{array}$ \\
\hline $3-1$ & KRAI & $\begin{array}{l}\text { - Initial groupping. Must al- } \\
\text { ways be } \mathrm{KRAI}>1 \text {. }\end{array}$ \\
\hline $5-6$ & KRAF & $\begin{array}{l}\text { - Last groupping. MIust al- } \\
\text { ways be KRAF } \geqslant \mathrm{KR} \Lambda \mathrm{I} \text {. }\end{array}$ \\
\hline $7-8$ & $K R A P$ & $\begin{array}{l}\text { - Step for executing intermedi- } \\
\text { ate grouppings. }\end{array}$ \\
\hline$* B^{*} \quad c a r d$ & & FORMAT $(20 A 4)$ \\
\hline $1-80$ & FR1 & $\begin{array}{l}\text { - Format of time series input } \\
\text { data. It must be like ( } \mathrm{A} 3 \text {, spe- } \\
\text { cifications for input data). Col- } \\
\text { umns } 1-3 \text { cannot be used. This } \\
\text { restriction is used to allow an } \\
\text { indefinite number of time se- } \\
\text { ries input data cards, the end } \\
\text { of which is reached when the } \\
\text { program read the } * \mathrm{I}^{*} \text { card. }\end{array}$ \\
\hline
\end{tabular}




\begin{tabular}{|c|c|c|}
\hline $\begin{array}{l}\text { Card } \\
\text { columns }\end{array}$ & $\begin{array}{l}\text { Corresponding } \\
\text { variable }\end{array}$ & Description \\
\hline$* C^{*}$ card & & FORIIAT $(20 \mathrm{~A} t)$ \\
\hline$* D^{*}$ card & FR2 & $\begin{array}{l}\text { - Format of output data to be } \\
\text { put on standard output tape. } \\
\text { FORMAT (20At) }\end{array}$ \\
\hline $1-80$ & FR. & $\begin{array}{l}\text { - Format according which one } \\
\text { can have the elements of mean } \\
\text { epoch on logical tape } 8 \text {, from } \\
\text { the second record on. }\end{array}$ \\
\hline * $b^{*}$ card & & FORIALT $(4 \mathrm{I} 3)$ \\
\hline $1-9$ & NISS & $\begin{array}{l}\text { - Number of time series data } \\
\text { contained in each input card. }\end{array}$ \\
\hline $3-4$ & NTPI & $\begin{array}{l}\text { - Logical tape number of input } \\
\text { (5 if input is from punched } \\
\text { cards). }\end{array}$ \\
\hline $5-6$ & $\mathrm{KE}$ & $\begin{array}{l}\text { - Number of decimal figures if } \\
\text { conversion is used }(*) .\end{array}$ \\
\hline $7-8$ & IT & $\begin{array}{l}->0 \text { if input conversion is } \\
\text { required }\left(^{*}\right) \\
-\leqslant 0 \text { if input conversion not } \\
\text { required }\left({ }^{*}\right) .\end{array}$ \\
\hline$* F^{*}$ card & & FORMAT (3I3) \\
\hline $1-2$ & NKPO & - Number of superposed epochs \\
\hline $3-4$ & NOPR & $\begin{array}{l}\text { - Number of elements preced- } \\
\text { ing } q_{i} \text { in the epoch }\end{array}$ \\
\hline$\tilde{0}-\mathbf{6}$ & NODO & $\begin{array}{l}\text { - Number of elements successive } \\
\text { to } q i \text { in the epoch. }\end{array}$ \\
\hline
\end{tabular}

$\left({ }^{*}\right)$ One must use conversion when time series input data are punched as integer constants having the sign (hole zone) over the less significant figure of the number. In this case each field of width $w$ containing the number, is considered like it were formed of two sequential fields: the lst of integer-type of width $v-1$, the 2nd of alphanumerie-type of width 1 . i.e.: if number 12.125 is punched according to the format specification F7.3 no conversion is required, being a Fortran number (in this case $I T-O)$. The character string $1212 \mathrm{~N}$ (where $N$ means holes 5 and 11 , minus sign overpunched) columns of the card, punched in a field of width $w=5$ for having the same value as the above one, must be read according to the format specification $I 4, A I$ and $m u s t$ be $K E=3$ (decimal figures of the number) and $I T \neq 0$. 


\begin{tabular}{|c|c|c|}
\hline $\begin{array}{l}\text { Card } \\
\text { columns }\end{array}$ & $\begin{array}{l}\text { Corresponding } \\
\text { variable }\end{array}$ & Description \\
\hline${ }^{*} G^{*}$ card & & FORMAT $(16 \mathrm{I} 5)$ \\
\hline $\begin{array}{r}1-\mathrm{n} \\
(n \leqslant 80)\end{array}$ & $\mathrm{KPO}$ & $\begin{array}{l}\text { - Index of } q_{i} \text { in the time series } \\
\text { input }\left({ }^{*} \mathrm{H}^{*} \text { card). }\right.\end{array}$ \\
\hline$* H *$ card & & FR1 format (see ${ }^{*} \mathrm{~B}^{*}$ (ard) \\
\hline $\begin{array}{c}4-n \\
(n \leqslant 80)\end{array}$ & $\begin{array}{l}\text { EL } \\
(\mathrm{KA}, \mathrm{KB})\end{array}$ & - Time series input data. \\
\hline$* I^{*}$ card & & FORMAT (A3) \\
\hline $1-3$ & KEND & $\begin{array}{l}\text { - The work END must be pun- } \\
\text { ched in the corresponding col- } \\
\text { umns. This card notifies the } \\
\text { program that all the cards } \\
\text { containing time series input } \\
\text { data have been read. }\end{array}$ \\
\hline$* J *$ card & & FORMAT (I3) \\
\hline $1-3$ & NGRU & $\begin{array}{l}\text { - Number of groups of ele- } \\
\text { ments to be discarded. If no } \\
\text { groups be discarded NGRU } \\
=\mathrm{O} \text { or blank. }\end{array}$ \\
\hline$* K^{*} \operatorname{card}$ & & FORMAT $(8(2 \mathrm{I} 5,3 \mathrm{X}))$ \\
\hline & NGRUI, NGRUF & $\begin{array}{l}\text { - Index of the initial and last } \\
\text { elements for each group to be } \\
\text { discarded among the time se- } \\
\text { ries input data. } \\
\text { - If NGRU = O or blank this } \\
\text { card must be omitted. }\end{array}$ \\
\hline$* L^{*}$ card & & FORMAT $(\mathrm{I} 4,2 \mathrm{I} 3,5 \mathrm{E} 14.6)$ \\
\hline & $\begin{array}{l}\text { This card may } \\
\text { the first record }\end{array}$ & $\begin{array}{l}\text { be punched from } \\
\text { on logical tape } 8 \text {. }\end{array}$ \\
\hline $1-4$ & LEPO & $\begin{array}{l}\text { - Number of elements of the } \\
\text { mean epoch. }\end{array}$ \\
\hline $5-7$ & NOPR & - See $* \mathrm{~F}^{*}$ card. \\
\hline $8-10$ & NKPO & - See $* F^{*}$ card. \\
\hline
\end{tabular}




\begin{tabular}{|c|c|c|}
\hline $\begin{array}{l}\text { Card } \\
\text { columns }\end{array}$ & $\begin{array}{l}\text { Corresponding } \\
\text { variable }\end{array}$ & Description \\
\hline \multicolumn{3}{|c|}{${ }^{*} L^{*}$ card (cont.) } \\
\hline $11-24$ & SIGM $\Lambda$ (1) & - Variance of the mean epoch. \\
\hline $25-38$ & $\mathrm{~S}(1)$ & $\begin{array}{l}\text { - Significance level of the mean } \\
\text { epoch. }\end{array}$ \\
\hline $39-52$ & SIGR2 & - Mean variance of data series. \\
\hline $53-66$ & SE & $\begin{array}{l}\text { - Standard deviation of data } \\
\text { series. }\end{array}$ \\
\hline $67-80$ & DIFVER (1) & SIGMA (1) - SIGR2/NKPO \\
\hline$H^{*}$ card & & FR3 format (see ${ }^{*} \mathrm{D}^{*}$ card) \\
\hline & ELMI & $\begin{array}{l}\text { - Elements of mean epoch. They } \\
\text { may be punched from the } \\
\text { second record on from logical } \\
\text { tipe } 8 \text {. }\end{array}$ \\
\hline
\end{tabular}

Comment'.

In the following pages it has been reproduced the list of the described program.

The authors have mainly contributed each in their activity field.

Timing.

1) It takes $7^{\prime \prime}$ to elaborate 1000 elements of stationary time series, the length of the epoch being 100 , corresponding to $n-10$, to group from 1 to 10 step 1 , and to find the local maxima.

2) It takes $1^{\prime \prime}$ to elaborate the restart procedure groupping from 4 to 9 .

ACKNOWLEDGEMENT.

Prof. 1. Clementel made easy the IBM 7094/7040 DCS computers utilisation at the Centro di Calcolo del CNEN in Bologna (SHARE Installation BI). 


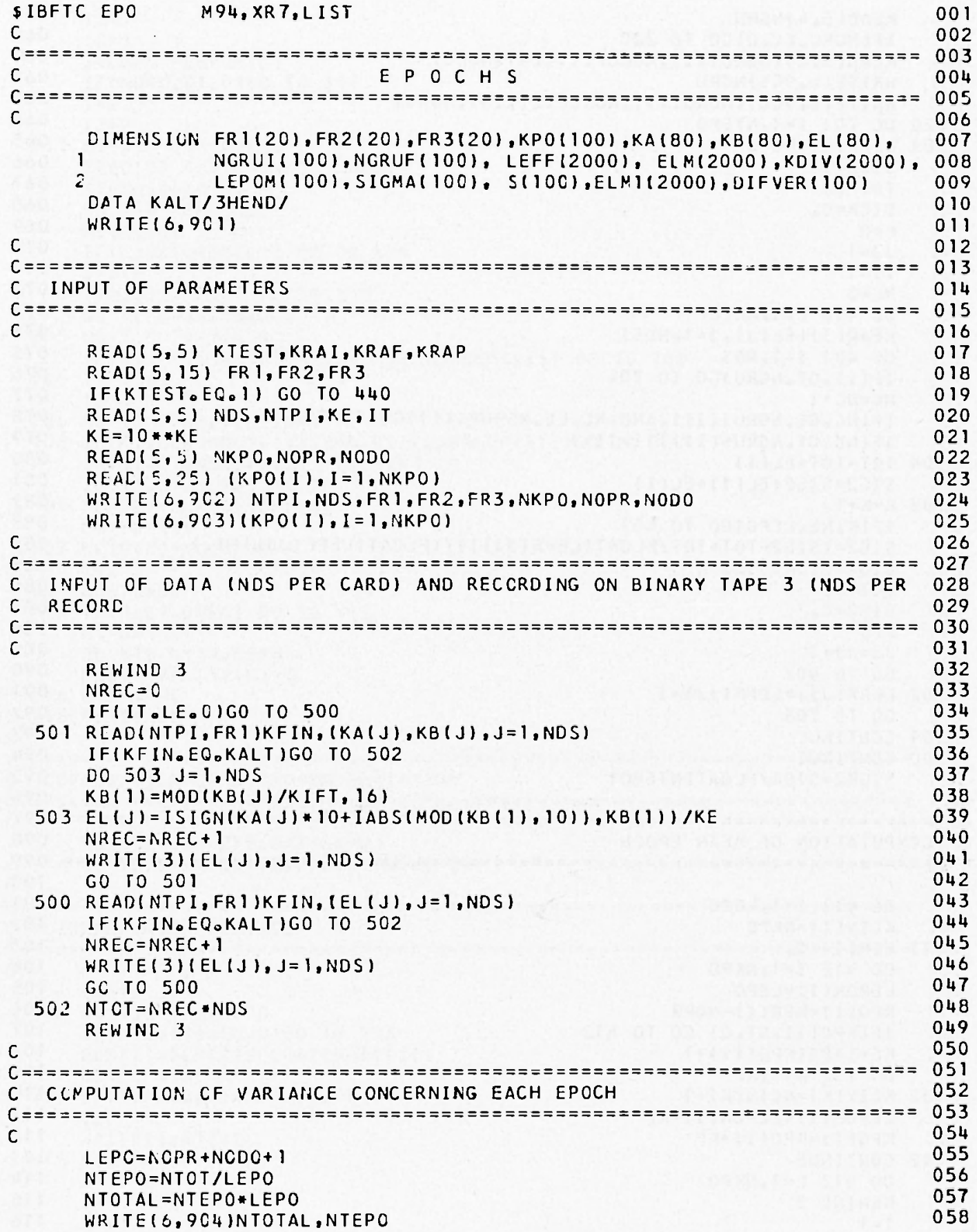


P.EAD $(5,4) N G R U$

IF (NGF.U.EG.0)GO TO $72 \mathrm{C}$

REAU! 5,6 ) (NGRUI(I),NGRUF ( I), I = I, NGRU)

061

WRITE $(6,905)$ NGRU

062

WRITE( 6,9 96) (NGRUI I ), NGRLF (I), I = , NGRU)

063

$7 \angle 0$ DC $701 \mathrm{I}=1$, NTEPO

$701 \operatorname{LEFF}(I)=L E P C$

$S I G 2=C$.

TOT $=0$ 。

SICR $=0$ 。

064

065

066

$K=0$

067

$\mathrm{J} J$
$\mathrm{H}=1$

068

$I I=1$

069

$11=1$

070

$N C=0$

071

DC $40 \mathrm{C} L=1$, NREC

072

$\operatorname{READ}(3)(E L(\mathrm{~J}), \mathrm{J}=1, N D S)$

073

DC $401 \mathrm{I}=1$, NDS

074

IFIII.GT.NGRU)GO TO 704

075

$N C=N C+1$

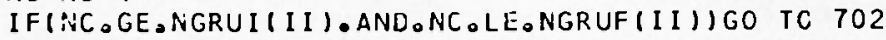

076

077 I F (NC,GT •NGRUF ( I I ) I I I I I + I

$704 \mathrm{TCT}=\mathrm{TCT}+\mathrm{EL}(\mathrm{I})$

$S I G 2=S I G 2+E L(I) * E L(I)$

$703 k=K+1$

$I F(K . N E \cdot L E P C) G O$ TO 401

082

$S I G 2=(S I G 2-T O T$ TOT/FLOAT(LEFF(JJ)))/(FLOAT(LEFF(JJ))-1。)

083

$S I G R=S I G R+S I G 2$

084

$\mathrm{T} C \mathrm{~T}=0$.

085

086

SIG2 $=\mathrm{C}$.

087

$K=0$

088

$J \mathrm{~J}=\mathrm{J} J+1$

GC TO 401

$702 \operatorname{LEFF}(\mathrm{JJ})=\operatorname{LEFF}(J \mathrm{~J})-1$

089

090 GJ TO 703

091

092

401 CCNTINUE

093

400 CONTINUE

$S I G R 2=S I G R / F L O A T(N T E P O)$

C COMPUTATION CF MEAN EPOCH

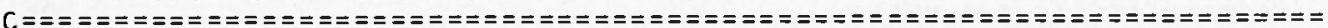

$\mathrm{C}$

DC $411 I=1, L E P O$

099

100

101

$K[$ IVII I $=N K P O$

102

103

101

CC $412 \mathrm{I}=1$, NK PO

LEPOM ( I ) $=$ LEPO

105

$K P O(I)=K P C(I)-N O P R$

106

IF(KPC(I).GT.O) GO TO 412

107

$K F=I A E S(K P O(I))+1$

108

DC $732 \mathrm{~K}=1, \mathrm{KF}$

109

$732 K C I V(K)=K O I V(K)-1$

110

LEPOM (I) $=\operatorname{LEPOM(I)-KF}$

$K P O(I)=K P O(I)+K F$

111

112

412 CONT INUE

113

DO $41 \geq L=1$, NKPO

114

REWINC?

115

$I=1$ 
$I I=I$

$12=1$

$J=L E P O-L E P O M(L)$

IFINGRU.GT.O)GO TO 711

$\mathrm{I}=2$

$12=2$

711 CC $414 \quad L 1=1$, NREC

$\operatorname{REAC}(3)(E L(L 2), L 2=1, N D S)$

$K T=N D S *(L 1-1)$

CO $414 \quad L 2=1$,NDS

$K I=K T+L 2$

IF(KI.LT.KPO(L)) GO TO 414 $\mathrm{J}=\mathrm{J}+1$

IF(J.GTOLEPO) GO TO 413

GC TO $(705,706)$, I

705 DC $71 C$ IG $=1$, NGRU

IF(KI॰LEONGRUIIII) OOR॰KI॰LEのNGRLF(II)) GO TO 708

710 II $=I I+1$

$12=2$

706 GO TO $(708,709), 12$

708 IF(KI。GE。NGRUII II) \&AND॰KI,LE。NGRUF(I I))GO TO 707 IF (KI。GT。NGRUF( I I ) I I I I I + I

IF ( I I G $G$ ०NGRU) I $2=2$

$709 \operatorname{ELM}(J)=\operatorname{ELM}(J)+E L(L 2)$

GC TO 414

$707 K[I V(J)=K[I V(J)-1$

$\mathrm{I}=\mathbf{2}$

414 CONTINUE

IF(J.CT.LEPC) GO TO 413

$\mathrm{J} \mathrm{l}=\mathrm{J}+\mathrm{l}$

DC $416 K=J 1, L E P O$

$K C I V(K)=K C I V(K)-1$

C

416 CCIITINUE

413 CONT INUE

117

118

119

120

121

122

123

124

125

126

127

128

129

130

131

132

133

135

136

137

138

139

140

141

142

143

144

145

146

147

148

149

150

151

152

153

C CCNPUTATICN CF STANDARD DEVIATION

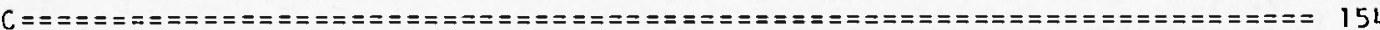

$\mathrm{C}$

TSIGR 2 = SIGR2/FLOAT (NKPC)

155

156

157

158

159

160

161

162

163

164

165

166

167

168

169

170

171

172

173

174 
DC $42 ! I=1, L E P O$

IF (KDIVIII,NE.0)GO TO 422

IF(J.EQ.2)GO TO 423

$J=2$

$\mathrm{IN}=\mathrm{I}$

423 I $F=I$

GC TO 421

1,22 IFIJEEQ.1)GO TO 421

$J=1$

IFIINOEG.I)GO TO 426

427 DC $42 \leq I M=I N$, IF $I M I=I N$

$425 E L M(I M)=E L M(I M 1-1)+E M E$ GO TO 421

426 IF(IFOEGOLEPO)GO TO 43 I

$I A=1$

430 ELM(IN) =EME

GO TO 421

431 WRITE $(6,910)$

COO TO 432

421 CCNT INUE

$T K P O=\Lambda K P C$

CALL VARIELM, SIGMA, S, 1, LEPO, 1, TKPO, SIGR2, DIFVER) i $3=3$

912 WRITE $(6,9 C 7)$ SIGR 2, SE, SIGMA $(1)$, S $(1)$, DIFVER 11$)$

WRITE $(6, F R 2)(E L M(J), J=1, L E P O)$

$K K=1$

WRITE $(6,1 C 1 C) L E P O, K K, S I G M A(K K), S(K K), D I F V E R(K K)$

IF (KTEST。EQ. I) KK $=$ KRAI -1

DC CIC KR.A=KRAI, KRAF, KRAP

$K K=K K+1$

CALL RAC (ELM, ELMI, LEPO, NOPR, KRA, LEPRA, IER)

IFI IER.EG. IIGC TO 640 
WR I TE $(6,643) \mathrm{KK}$

$\begin{array}{ll}\text { GO TO } 678 & 234 \\ & \end{array}$

C

644 DC $645 I=I 3, K K$

$I I=I$

IF(S(II-2)。CE.S(II-1)。OR。S(II-1).LE.S(I))GC TC 645

$K R A=K R A I+(I I-I 3) * K R A P$

IF (KTEST,EQ. I) KRA $=K R A+1$

CALL RAG (ELM, ELM 1, LEPO, NOPR, KRA, LEPRA, IER)

WRITE $(6,646)$ S (II-1), SIGMA (I I- I), KRA, KRA, LEPRA

END FILE 8

$C$

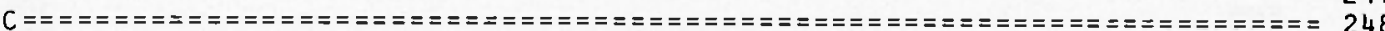

C IF KTEST $=1$ INPUT OF MEAN EPCCH TO RESTART A FCRNER COMPUTATION 249

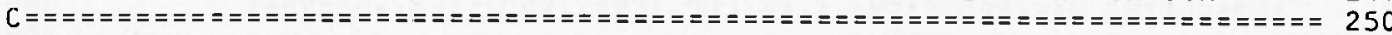

C

440 READ ( 5,9C8)LEPO,NOPR,NKPO,SIGMA (I),S(1),SIGR2,SE,DIFVER(1) 252

$T K P O=\Lambda K P O$

$I Z=K R A I+2$

WRITE $(6,916)$

READ (5,FR3) (ELM(I), I = 1, LEPO)

GO TO 912

$c$

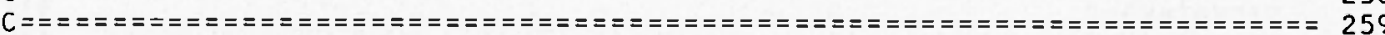

c

1. FORMAT (I3)

5 FORMAT ( 4 I 3$)$

6 FORMAT ( E (2I5, 3X))

5 FORMAT (20A4)

25 FORMAT ( 16 IS)

263

264

117 FORMAT $(15 X, 16)$

641 FORMAT $(1 \mathrm{HI}, 10 \mathrm{X}, 16 \mathrm{HGROLPPING}$ NUMBERI3,15H CANNOT BE MADE $5 \mathrm{X}, 6 \mathrm{HNOPR}=268$

II $6,10 X, 5 H K P . A=I 5)$

643 FORMAT (IHO, 10X, 15HTHE GROUPS ARE $12,41 \mathrm{H}$. THE LOCAL MAXIMUM CANNOT 270

1 BE DETERH INED).

646 FORMATIIHC, 10X, 3HS =E14.6, 8X,7HSIGMA =E14.6, 8X,8HGROUPING,I4,3H 272

IBY, I $3,8 X, 3 H R=, I 5)$

347 FCRMAT( $1 \mathrm{H} 1,10 \mathrm{X}, 12 \mathrm{HLOCAL}$ MAXIMA/11X,12(1H-),//1)

901 FCRMATI IHI, IOX, IIHE P O C H $5 / 11 \mathrm{X}, 1111 \mathrm{H}-1,1 / 1)$

902 FCRMAT $111 \mathrm{X}, 10 \mathrm{HINPUT}$ TAPEI $3 / 11 \mathrm{X}, 13 \mathrm{HDATA}$ PER CARDI4/11X2 IHTHE INPUT IFCRMAT IS 20A4/11X,2IHTHE PRINT FORMAT IS $20 A 4 / 11 X, 21 \mathrm{HTHE}$ PUNCH

2FCRMAT IS 20A4///1IX,2IHNUMBER OF POINTS GIIII4/1IX,34HNUMBER OF ITHE ELEMENTS PRECEDING QI4/11X,34HNUMBER OF THE ELEMENTS FOLLOHINC 4 QI4)

903 FORMAT( $11 \mathrm{X}, 31 \mathrm{HINDEX}$ OF SUPERPGSED PCIATS Q(I)//, $(11 \mathrm{X}, 16 I 6)) \quad 281$

904 FORMATI IHO, 10X,27HNUMBER OF UTILIZED ELEMENTSI $8 / 11 \mathrm{X}, 28$ HNUMBER OF C 282

IONSECLTIVE EPOCHSI6)

905 FORMATI IHC, 10X,5 IHNUMBER OF GROUPS OF CCNSECUTIVE ELEMEATS TO DISC 284 IAP.DI4)

906 FORMAT $111 \mathrm{X}, 66$ HINDEXES OF THE FIRST AND THE LAST ELEMENT TO DISCARD 286

I IN EACH GROUP//, (11X,5(2I6,3H*)1)

907 FORMATI IHC, 10X, 2 IHMEAN VARIANCE SIGR2EI5.6/

$111 X, 23 H S T A N D A R D$ LEVIATION SEE $15.6 /$

2 IIX, ZOHVARIANCE OF MEAN EPOCH SIGMAE 15.6/ 
$311 X, 22 \mathrm{HSIGNIFICANCE}$ LEVEL SE $15.6 /$

4 IIX, 64HVARIANCE OF MEAN EPOCH - MEAN VARIANCE/NUMBER OF EPOCHS 292 SDIFVERE $1506 / / / / 1$

908 FCRMAT $(14,213,5 E 14,6)$

209 FORMATI $1 H 0,10 X, 48$ HINDEX OF INTERPCLATED ELEMENTS IN THE MEAN EPOCH 295 1)

910 FORMAT $(1 \mathrm{H} 1,10 X, 40 \mathrm{HTHE}$ ELEMENTS OF MEAN EPOCH ARE ALL ZEROS)

914 FORMAT (1HO, 10X, 1OHEND OF JOB/ $11 X, 10(1 \mathrm{H}=1)$

916 FORMAT $(1 \mathrm{H} 1, / / 1,11 \mathrm{X}, 31 \mathrm{H}$ HESTART OF A FORMER COMPUTATION/11X,3111H-), $1 / / / 1$

1010 FORMAT(1HO/1HO, 7X, IHR, 7X, 6HGRCUPS, 10X, 5HSIGMA, 17X, 1HS, 16X, 6HDIFVE IR//2I 10,3E20.6)

$\mathrm{C}$

$\mathrm{C}$

$\mathrm{C}=$

END

SIBFTC VRI M94,XRT,LIST

SURROUTINE VARIEPO, SIGMA, S, KK, LUP, TKRA, TKPO, SIGR2, UIFVER)

c

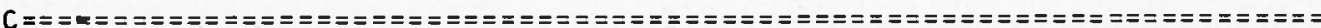

DIMENSION EPO $(1)$, SIGMA $(1)$, S 11$),$ DIFVER $(1)$

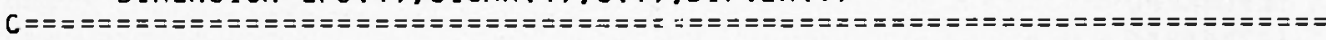

$\mathrm{C}$

$T L=L U P$

DIF $=S$ I GR $2 / T K P O$

$T C T=0$.

$\operatorname{SIGMA}(K K)=0$.

DC 1 I $=1$, LUP

$T C T=T C T+E P O(I)$

$S I G M A(K K)=S I G M A(K K)+E P O(I) * E P C(I)$

1 CONTINUE

SIGMA $(K K)=(S I G M A(K K)-T O T * T O T / T L) /(T L-1$.

$S(K K)=S Q R T((T L-1) / 2)=,(T K P C=T K R A * S I G M A(K K) / S I G R 2-1$.

DIFVER $(K K)=S I G M A(K K)-D I F$

IF (KK。EQ.1) RETURN

WRITE $(6,2)$ LUP, KK, SIGMA $(K K), S(K K)$, DIFVER(KK)

RETURN

2 FCRMAT (2I 10,3E20.6)

END

SIBFTC RGR M94, XR7,LIST

SUBROUTINE RAG(EPOR, EPKK, LEPO, NOPR, KRA, LEPRA, IER)

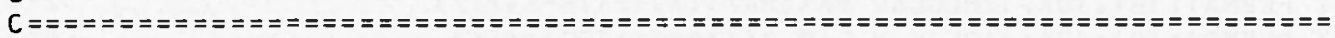
CIMENSION EPOR $(1)$,EPKK(1)

$I E P:=1$

NO $=$ NOPR-KRA/2

IF (NO_LT GKPA) CO TO 1

$I N=M O[(N O, K R A)+1$

I IFINO.LT•CIGO TO 7

2 I $I=I N$

$12=I N+K R A-1$

L [PRA $=\{$ LEPO-IN+ I) /KRA

DC $3 \mathrm{I}=1$, LEPRA 
$I 1=I 1+1$

$\mathrm{I} l=\mathrm{I} 2+1$

$I 2=I 2+K R A$

3 CONTINUE

353

DO $5 \mathrm{I}=1$. LEPRA

354

5 EPKK(I)=EPKKII)/FLOAT(KRA)

355

RETURN

7 IER $=2$

RETURN

356

357

358

359

END

360

\section{REFERENCES}

(1) Citapman S., Bartels J., Geomagnetism. Oxford (I940).

(2) Dorman I. I., Cosmic Ray Variations. Moscow (1957).

( $\left.{ }^{3}\right)$ Chree C., Some Phenomena of Sunspots and of Terrestial Magnetism. Pat. II, " Roy. Soc. Phil. 'Trans.", 213, 245 (I9I3).

(4) GaLli M., RANDI P., On the design of the optimum numerical filter with a prefixed response. "Annali di Geofisica", XX, 4 (1967).

(5) Attolini M., Dall'Olio L., Guerrieri V., Raxdi P., A computation program for numerical filtering. "Annali di Geofisica ". XXI, 2 (1968). 